\title{
El carácter sexo-genérico de la represión estatal en la Argentina de la década del setenta
}

\author{
The sex-gender dimension of the state repression in Argentina of the seventies
}

\author{
LAURA MERCEDES RODRÍGUEZ AGUERO \\ INCIHUSA CONICET \\ lrodriguezaguero@gmail.com \\ https://orcid.org/0000-0001-7839-7659 \\ DÉBORA D`ANTONIO \\ CONICET \\ deboradantonio@hotmail.com \\ http://orcid.org/0000-0001-6326-1345 \\ http://dx.doi.org/10.15304/sm.31.6018
}

\section{RESUMEN}

A partir de la idea de que la represión sexuada llevada a cabo por la última dictadura militar argentina (1976-1983) tuvo un carácter estructural y sistemático, en este trabajo nos proponemos analizar de qué modo esa dimensión se manifestó en las facetas legales e ilegales, visibles y ocultas de la trama estatal. Para ello partimos de la hipótesis de que las políticas de destrucción de la subjetividad genérica que el régimen practicó de manera oculta en los espacios de encierro -legales e ilegalesfueron la contracara de lo que las autoridades militares clamaban en sus discursos públicos, en los que primaba una prédica restauracionista de los roles de género acorde con la proyección de una cultura argentina derivada de la tradición occidental y cristiana.

Palabras clave: represión, género, historia argentina reciente.

\begin{abstract}
Starting from the idea that the sexual repression carried out by the last Argentine military dictatorship (1976-1983) had a structural and systematic character, in this paper we will analyze how the generic sex character of the repression was manifested in the dimensions legal / illegal, visible / hidden of the state plot. For this we start from the hypothesis that the policies of destruction of the generic subjectivity that the regime practiced in a hidden way in the spaces of confinement -legal and illegal- were the counterpart of what the military authorities cried out in their public speeches, where they had restorative preaching of gender roles, "appropriates" to a hypothetical Argentine culture derived from the Western and Christian tradition.
\end{abstract}

Keywords: repression, gender, argentine recent history. 


\section{INTRODUCCIÓN}

El estudio de la represión política estatal durante las décadas del sesenta y setenta en la Argentina ha tenido un significativo desarrollo en el campo académico local en los últimos años al punto de constituirse en uno de los problemas de mayor relevancia de la agenda historiográfica. Distintas investigaciones han abordado las lógicas, los dispositivos y los mecanismos que estructuraron los procesos represivos demostrando principalmente su carácter multiforme. La idea inicial que se manejó, por ejemplo, de un "enemigo interno" identificado con los militantes de las organizaciones político-militares, junto a la de perpetradores vinculados con las Fuerzas Armadas y de Seguridad fue notablemente amplificada. Aparecieron, por un lado, como blanco de la persecución a sectores de la clase trabajadora, de la juventud, mujeres en situación de prostitución u homosexuales y, por otro lado, se identificaron una variedad de nuevos agentes estatales que ejercieron la represión en su condición de parteras, religiosas, personal médico o asistentes sociales, entre otros. La periodización rígida que marcaba el comienzo del terror el 24 de marzo de 1976, día del golpe de Estado, fue matizada y reencuadrada en marcos temporales más abiertos y extendidos. De modo que se mostraron por medio de la investigación empírica líneas represivas de largo plazo, por ejemplo, desde mediados del siglo $\mathrm{XX}$, adquiriendo con ello mayor especificidad histórica la experiencia de la última dictadura militar. Las escalas de análisis se multiplicaron y enlazaron las dinámicas represivas locales con las nacionales y con regionales, y en algunos casos, con las transnacionales como, por ejemplo, respecto de las coordinaciones represivas interestatales que hallaron su punto más desarrollado en la Operación Cóndor de fuerte impacto en el Cono Sur.

El conjunto de estos trabajos visibilizó aristas del funcionamiento represivo del Estado desconocidas tan sólo un tiempo atrás. Esto es así, porque inicialmente en la renovación que se produjo en estas investigaciones, el género y la sexualidad no adquirieron el grado de dimensión analítica sustantiva a pesar de que existía una larga contribución y distintos estudios elaborados desde esta perspectiva. ${ }^{1}$ Se podría decir que mientras los "hallazgos interpretativos" se constituyeron en patrimonio del conjunto de estos trabajos, los "hallazgos de género" quedaron delimitados a las pesquisas especializadas en torno al género y la sexualidad. ${ }^{2}$ Solo recientemente, y frente al impacto que han tenido los testimonios en los juicios de lesa humanidad, centrados sobre todo en la violencia sexual

1 Un trabajo ocupado en mostrar y ponderar las intersecciones entre la Historia Reciente, la Historia de las Mujeres y los Estudios de Género puede hallarse en D’Antonio y Viano (2018). Allí se demuestra que, desde mediados de la primera década del siglo XX, el campo de indagación de la historia de las mujeres y de los estudios de género en la Argentina contaba al momento del encuentro con la Historia Reciente profesional, un recorrido de varios años, tradiciones analíticas y fuertes debates propios.

2 Vale la pena señalar brevemente que existen distintos núcleos académicos (grupos, cátedras, programas, institutos, investigadores, etc.) que, desde por lo menos dos décadas atrás, se proponen reponer la generización de los procesos históricos del pasado reciente argentino, de las instituciones y de los sujetos que actuaron en él. Una experiencia prolífica que ha tomado cuerpo en la producción científica y en la formación de recursos. 
ejercida en los espacios de detención, y en el marco de la construcción política de los nuevos feminismos es que esta tendencia ha empezado a revertirse.

Caben entonces algunas preguntas iniciales de carácter epistemológico para organizar el trabajo que aquí presentamos: ¿debe la dimensión de género tener un lugar de preeminencia en los análisis históricos o pueden tan solo ser parte de los estudios de especialización sobre el período?, ¿en esta dirección, la dimensión de género es meramente agregativa?; ¿cuáles son las implicancias de incorporar esta perspectiva al análisis de la represión estatal?; ¿qué otros objetos de estudio se ponen en foco bajo este paradigma?; ¿cuál es la contribución específica de la cuestión de género al campo de estudios de los Estados represivos del Cono Sur en particular?; ¿qué significa pensar la represión ejercida por agentes estatales generizados?; y, por último, ¿de qué manera se manifiesta el carácter sexuado de la represión cuando abordamos la problemática de los "perpetradores"?

En este trabajo, a partir de los interrogantes planteados, analizaremos de qué modo el carácter sexo-genérico de la represión se manifestó en las dimensiones legales e ilegales, visibles y ocultas de la trama represiva estatal. Para ello partimos de la hipótesis de que las políticas de destrucción de la subjetividad genérica que el régimen practicó de manera oculta en los espacios de encierro legales e ilegales fueron la contracara de lo que las autoridades militares clamaban en sus discursos públicos, en los que primaba una prédica restauracionista de los roles de género.

Apuntamos con estas reflexiones a contribuir con las líneas historiográficas que se proponen profundizar el conocimiento sobre la represión estatal en el pasado reciente, y que a la vez, se interesan en construir una historiografía y una gramática política feminista atenta a las formas generizadas que estructuraron el accionar represivo de los aparatos estatales.

\section{EL CARÁCTER SEXO GENÉRICO DE LA REPRESIÓN EN CIRCUITOS LEGALES E ILEGALES DE DETENCIÓN}

¿Por qué hablamos del carácter sexo genérico de la represión? Lo primero que debemos señalar es que durante los años del último régimen militar (1976-1983), la represión sexuada hacia las mujeres (y también hacia otras identidades genéricas) tuvo un carácter estructural. Para advertirlo resulta útil partir del hecho de que el combate a la denominada "subversión" se inscribió en una relación asimétrica entre los géneros sexuales. Esto encontró expresión en las acciones de persecución, tortura, encierro y exterminio que fueron ensayadas por los dispositivos represivos estatales y paraestatales.

La perspectiva de género ha tornado visibles a ciertos objetos y prácticas sociales, que lejos de ser secundarios, adquirieron en esta etapa un papel central. Al mismo tiempo el género es una dimensión analítica que no sólo suma temas y problemas que antes no habían sido considerados, sino que apuntala la indagación de las aristas que estructuran al conjunto del proceso represivo estatal, y que al igual que otras herramientas con- 
ceptuales, contribuye con una explicación de carácter integral de los procesos históricos (D’Antonio, Rodríguez Agüero, 2017).

Lo segundo que queremos marcar es el carácter diferencial de la represión. Esto significa que la misma establece una relación asimétrica y jerárquica entre los géneros, la cual se plasma en el carácter específico con el que se ejerce la represión hacia varones, mujeres y otras identidades no normativizadas. Un análisis en esta clave permite observar este carácter diferencial en el accionar de los aparatos represivos del Estado que forman parte de los circuitos de represión ilegal donde se emplazan los centros clandestinos de detención que generalizan la figura de la desaparición forzada de personas o en los circuitos legalizados como los de las cárceles del sistema penitenciario federal o del sistema penitenciario de jurisdicción provincial.

En este artículo nos concentraremos en dos prácticas represivas generizadas que afectaron especialmente a militantes y a trabajadoras estatales que estuvieron detenidas en el Centro Clandestino de Detención D2 dependiente de la policía provincial de Mendoza $^{3}$. Nos referimos a las prácticas de desmaternalización y al ejercicio de la violencia sexual.

La desmaternalización es un proceso que remite a la degradación y maltrato de las prisioneras madres y al deterioro intencional por parte de los agentes estatales penitenciarios del lazo filial (D’Antonio, 2016: 184 y 2011: 168). Allí se advierte cómo "el régimen militar subvirtió el orden de género y sexual en los espacios de encierro ocultos a los ojos de la sociedad yendo contra su prédica familiarista y restauracionista" (D’Antonio, Rodríguez Agüero, 2017: 9). La veneración pública que se forjaba hacia la figura de las madres tuvo su contracara en el trato ofrecido a las militantes "que convertían primero en desaparecidas para luego secuestrarles y sustituirles la identidad a sus hijos e hijas" (D 'Antonio, Rodríguez Agüero, 2017: 9). Pero también en el caso de las presas políticas de las cárceles legalizadas se agrega que "el poder penitenciario puso todos los mecanismos institucionales al servicio de interferir el vínculo con los menores" (D 'Antonio, Rodríguez Agüero, 2017: 9).

En esta dirección, vamos a analizar algunos casos de mujeres que fueron secuestradas en el marco de lo que se conoce como el Operativo Febrero del '76 o causa Rabanal para el Poder Judicial en la actualidad, ocurrido en la provincia de Mendoza. ${ }^{4}$ La infor-

3 Mendoza es una ciudad del oeste de la Argentina. Es la capital de la provincia que tienen el mismo nombre y que está ubicada en la llanura al este de la cordillera de los Andes. Es una zona de frontera que cuenta con distintos caminos para ingresar o salir de Chile.

4 El Operativo Febrero del '76 consistió en el secuestro de once delegados/as gremiales pertenecientes al sindicato Asociación de Trabajadores del Estado (ATE) y al ex Sindicato de Obreros y Empleados Públicos (SOEP), y en algunos casos a la Juventud Trabajadora Peronista (JTP) y Montoneros (y un niño y dos niñas), por fuerzas de la Policía de Mendoza, D2, el Cuerpo Motorizado, el Cuerpo de Infantería y la Dirección de Investigaciones. El operativo se desató tras la captura en la vía pública de Daniel Rabanal, el 6 de febrero de 1976. Luego sobrevinieron los secuestros de Marcos Ibáñez y Rodolfo Molina; de Fernando Rule, Silvia Ontivero y su hijo pequeño Alejo Hunau; de Stella Maris Ferrón y su hija Yannina Rossi, Alberto Muñoz, Ivonne Larrieu y la hija de ambos, María Antonia de apenas quince 
mación fue obtenida de las declaraciones testimoniales proporcionadas por las víctimas en el transcurso del IV Juicio por delitos de lesa humanidad de la ciudad de Mendoza. ${ }^{5}$

\section{PROCESOS DE DESMATERNALIZACIÓN Y VIOLENCIA SEXUAL EN LOS CENTROS CLANDESTINOS DE DETENCIÓN (CCD)}

Silvia Ontivero tenía 29 años, trabajaba en la Dirección de Comercio, de la cual era delegada gremial, militaba en la Juventud Trabajadora Peronista (JTP) y ATE (Asociación Trabajadores del Estado). Fue secuestrada junto a su compañero Fernando Rule y su hijo Alejo Hunau, de cuatro años de edad, y llevada al D2, donde según ha relatado, vivió los peores 18 días de su vida. En ese CCD fue golpeada e insultada frente a su hijo. A dicha situación se le sumó el hecho de que su secuestró se realizó mientras ella tenía en curso embarazo, y luego de las sesiones de tortura con picana eléctrica, sufrió un aborto, y un posterior legrado sin anestesia. Según relató en su declaración en el IV Juicio por delitos de lesa humanidad de Mendoza, con el paso del tiempo, supo que estos vejámenes le habían producido infertilidad. Silvia consignó en su testimonio judicial otros episodios de abortos sufridos por otras mujeres: "junto con otra compañera abortamos en el momento de la tortura, yo estaba de aproximadamente dos meses y medio y la otra detenida de cuatro meses. Luego del aborto espontáneo se presentó una persona que dijo ser médico y que realizó en carne viva el raspaje final". ${ }^{6}$ Después de su paso por el D2, Silvia fue trasladada a la Penitenciaría provincial -donde fue golpeada y se le impidió la visita de su hijo- y, posteriormente, trasladada a la cárcel de Villa Devoto en la ciudad de Buenos Aires. Recién recuperó su libertad en septiembre de 1982 a tan sólo un poco más de un año a la vuelta al Estado de Derecho. ${ }^{7}$ En los interrogatorios a los que fue sometida mientras estuvo en cautiverio, una de las amenazas recurrentes era que no volvería nunca más a ver a su hijo. Una intimidación que finalmente se cumplió ya que el padre del menor, aprovechando su aislamiento, y con la connivencia del poder judicial provincial, en octubre de 1977, logró que se dictaminara el abandono de hogar por su parte cuando era de público conocimiento que ella estaba en situación de encierro. La figura de abandono de hogar, avalada por un juzgado de familia, la llevó a perder la patria potestad sobre el niño y le impidió verlo durante los primeros seis años de vida. Fue recién once años después y tras una larga lucha que Silvia logró recuperarlo.

Ivonne Larrieu tenía 18 años, el 9 de febrero de 1976, cuando un grupo de tareas la secuestró de su domicilio junto con su hija María Antonia que había nacido el 25 de enero de ese mismo año. La mujer y la beba fueron trasladadas al D2, al igual que su marido

días, y de Miguel Ángel Gil (todos ellos el 10 de febrero); de Olga Vicenta Zárate, el 12 de febrero y de Guido Actis, el 20 de febrero.

5 Ver su registro en el blog del colectivo Juicios Mendoza: https://juiciosmendoza.wordpress.com/

6 https://juiciosmendoza.wordpress.com/2014/06/02/

7 https://juiciosmendoza.wordpress.com/2014/06/02/ 
y padre de la beba, Alberto Muñoz. Ivonne y Alberto, oriundos de Mar del Plata, eran militantes de la Unión de Estudiantes Secundarios (UES), organización ligada a la agrupación Montoneros de la izquierda revolucionaria del peronismo. Al detectar que eran vigilados y perseguidos, decidieron trasladarse a la ciudad de Mendoza. En el D2, Larrieu y su bebé fueron alojadas en una habitación vacía, sin muebles ni colchones. Durante por lo menos 4 días, no le proporcionaron comida ni agua, pero aún así pudo amamantar a su hija. Tampoco le facilitaron pañales por lo que para higienizar a su hija utilizaba pedacitos de la funda de la almohada con la que tenía vendada su cabeza. Una vez trasladada a la Penitenciaría, cuando Antonia tenía sólo 5 meses, debieron llevarla de urgencia al hospital Militar para operarla por una obstrucción intestinal ${ }^{8}$. En esa intervención le provocaron quemaduras en las nalgas, en apariencia con agua hirviendo. Ivonne en su declaración en el IV Juicio por Delitos de Lesa Humanidad señaló: “ella también estaba presa. Tenía 15 días y era una víctima más. Nos les importó nada, qué animales, si se moría, se moría"9.

En el caso de Stella Maris Ferrón, quien fue secuestrada el mismo día que Ivonne y trasladada también al D2, el trato fue bastante similar. Fue capturada junto a su hija Yanina de 10 meses y fue seriamente golpeada "y hasta le aplicaron corriente en su cuerpo con un cable conectado a un auto" ${ }^{10}$. Desde el momento de la detención de ambas, la familia de Ferrón se trasladó desde la provincia de Santa Fe a la de Mendoza para abocarse a la búsqueda de la pequeña. Sin resultados positivos decidieron regresar a Santa Fe. En esa ciudad, la madre de Stella solicitó la mediación del entonces obispo, Monseñor Zaspe, quien aparentemente se comunicó con la curia mendocina hasta que finalmente dieron con el paradero de la criatura. La hija de Ferrón había quedado en poder del comisario Juan Félix Amaya, funcionario de la seccional $25^{\circ}$. En la actuación policial consta que Amaya "por peligro moral y material se hace cargo de la niña". Sin embargo, cuando la entregó a los padres de la detenida el día 12 de marzo: "Yanina tenía el mismo enterito que el día del secuestro -había pasado más de un mes- con olor a amoníaco, estrabismo en los ojos e infecciones varias". Ya con Stella, en la cárcel, debió soportar un simulacro de fusilamiento estando en brazos de su mamá. A raíz del clima de inseguridad y agresión que vivían, Ferrón decidió entregar la nena a sus abuelos. "Las consecuencias psíquicas han sido severas", señalaba el informe médico con el que Stella Maris concluyó su testimonio en sede judicial. ${ }^{11}$

Este breve recorrido por los cuatro casos descriptos permite observar cómo la institución de la maternidad y el lugar de las mujeres como pilares de la misma que era defendido y "militado" por el régimen castrense como una de las bases de la sociedad occidental y cristiana, sin embargo, fue atacada brutalmente en los circuitos represivos

8 https://juiciosmendoza.wordpress.com/audiencia-134-alegato-fiscalia-iii-el-descenso-del-d2

9 https://juiciosmendoza.wordpress.com/audiencia-134-alegato-fiscalia-iii-el-descenso-del-d2/v

10 https://juiciosmendoza.wordpress.com/2014/06/16/

11 https://juiciosmendoza.wordpress.com/2014/06/16/ 
clandestinos y también en los legales. Tal como se señaló, esto incluyó prácticas como las de secuestro y tortura en madres y niños y niñas a los que se les aplicó electricidad o se les provocó quemaduras en distintas zonas del cuerpo. También se llevaron adelante simulacros de fusilamientos, se indujeron abortos (con posterior legrado sin anestesia), se les quitó la posibilidad de ejercer la patria potestad a las mujeres presas justificado bajo la figura "abandono de hogar" y, por último, se apropiaron ilegítimamente de sus hijos e hijas sustituyéndoles la identidad.

Diversos trabajos han abordado la violencia sexual como una práctica que no afectó únicamente a las mujeres pues algunos varones también la padecieron. No obstante, parece haber sido infringida en su mayor parte sobre ellas, y dentro de este grupo, sobre aquellas mujeres que estuvieron secuestradas en distintos CCD (D’Antonio, 2012; Bacci et al. 2014; Aucía et al., 2011, Ciriza, 2014; Balardini et al. 2011; Sutton, 2018). Tal como ha sido señalado, a partir de los testimonios "surge nítidamente que las agresiones sexuales a las que fueron sometidos los allí detenidos no configuraron situaciones aisladas, sino que formaron parte de este plan general de aniquilamiento y degradación de la subjetividad de las personas" (Balardini et al., 2011: 8). Si bien mujeres y varones fueron víctimas de violencia sexual, para las mujeres esta tuvo un carácter rutinario y extendido:

\footnotetext{
"desde el momento en que todas las víctimas refieren alguna de estas manifestaciones: manoseos, amenazas de violación, burlas y humillación de contenido sexual, desnudez forzada y expuesta, violación con acceso carnal, violaciones grupales, violaciones con objetos, servidumbre, mutilación, abuso sexual, acoso sexual, exhibicionismo, golpes y descargas eléctricas en los genitales, etc. (Aucía, 2011: 63).
}

Otra dimensión que debe ser ponderada en relación con el accionar represivo de las prácticas analizadas es la existencia de elementos novedosos y de otros habituales. La violencia sexual, por ejemplo, no fue algo inédito, sino que más bien se reactualizó en un contexto de violencia estatal y paraestatal. Al respecto Marta Vasallo señala cierto "continuum en la violencia sexual contra las mujeres, que dificulta establecer una frontera nítida entre los hechos generados por la represión ilegal y muchos que se producen sin necesidad de ese marco" (Vasallo, 2011: 3). Vasallo también advierte que "todas las mujeres y adolescentes internadas en asilos, correccionales, cárceles, psiquiátricos, son especialmente vulnerables a los abusos de sus guardianes" (Vasallo, 2011: 22). El continuum entre la violencia sexual ejercida contra las mujeres en el marco de crímenes de lesa humanidad y en el de delitos comunes no se aplicaría, sin embargo, a los hombres, advierte esta autora. En la misma dirección Celina Berterame señala que:

\footnotetext{
"la violencia sexual ejercida contra mujeres y hombres durante la última dictadura cívico- militar no es más que una manifestación exacerbada de las formas más burdas de discriminación y desigualdad existentes en la sociedad (...) resulta un mero continuum de la violencia de género que las mujeres han sufrido históricamente" (Berterame, 2011: 25).
} 
En el caso en análisis, la violencia sexual fue una práctica que parece haber sido aplicada a gran parte de las detenidas del Operativo Febrero del 76, tal como ha sido relatado por las propias víctimas de la represión en los juicios de lesa humanidad. Teniendo en cuenta que este operativo se dirigió, como ya se señaló, hacia trabajadores/as estatales y militantes de la JTP, realizamos una entrevista a un ex delegado del gremio del SOEP ${ }^{12}$, quien relató cómo hacia mediados de 1974, bajo un gobierno constitucional como el de María Estela Martínez de Perón en el cual operaban bandas paraestatales "ajusticiando comunistas", comenzó la persecución de trabajadores/as estatales. En un contexto de correlación de fuerzas desfavorable para los sectores radicalizados de la clase trabajadora, en junio de ese año, una asamblea del SOEP, que sesionaba en el sindicato de obreros mosaístas, fue atacada a balazos. Frente al temor y a los obstáculos que el nuevo gobierno provincial interponía a experiencias gremiales alejadas de la tradición sindical peronista, este sindicato decidió disolverse. Rule recuerda que uno de los hechos que comenzó a causar temor y preocupación fue justamente el ataque sexual a una delegada:

\footnotetext{
"Recuerdo que los compañeros más asustados o débiles no te saludaban. Habían secuestrado a una compañera a fines del 74...la violó toda la comisaría... pero casi no se hablaba de eso". ${ }^{13}$
}

Este hecho, lejos de ser aislado, fue anticipatorio de lo que ocurriría más adelante. A partir de los casos analizados podemos afirmar que la violencia sexual fue una práctica diaria y extendida no sólo a las mujeres secuestradas en el marco del Operativo Febrero del '76 sino a la mayor parte de aquellas que pasaron por el ex D2. Silvia Ontivero declaró que fue atacada sexualmente todos los días de su cautiverio, reiteradamente, de día y de noche: "Tuve que soportar la violación de cuanto señor estaba de turno, varias veces al día. No solo yo, todas las mujeres". Las violaciones se producían en las celdas, salvo una vez en que fueron todas las mujeres trasladadas, obligadas a desnudarse y sometidas a todo tipo de vejámenes. Silvia compartió cautiverio con Stella Maris Ferrón y Vicenta Olga Zárate (otra delegada estatal), quienes también fueron objeto de ataques sexuales, según lo detalló la propia testigo. "Pagamos el precio de ser mujeres", reflexionó Ontivero al referirse a los tormentos sexuales que sufrieron ella y sus compañeras en el estrado judicial. Ivonne Larrieu y Stella Maris Ferrón también declararon sobre las torturas y vejámenes sexuales sufridos por ellas y el resto de las detenidas. El caso de Vicenta Olga Zárate también es emblemático. Vicenta tenía 45 años al momento de su secuestro, trabajaba en ENTEL (una empresa telefónica estatal) y era delegada gremial. El 12 de febrero estaba internada en el Policlínico de Cuyo, tras haber sido operada de una patología en el útero en la jornada inmediatamente anterior, y allí se le asignó una custodia policial

\footnotetext{
12 Entrevista realizada por Laura Rodríguez Agüero, a Fernando Rule, ex SOEP y militante Montonero, 62 años, Mendoza, marzo de 2013.

13 Ibídem.
} 
hasta el 21 de febrero, cuando una mujer ingresó a la sala, vendó sus ojos, le colocó gafas oscuras y el personal de Infantería la trasladó al D2. Esa misma noche, y en otras oportunidades también, fue violada en el interior de una minúscula celda. Días después fue sumada a una "pirámide humana" que provocó la muerte en el ex D2 del delegado estatal Miguel Ángel Gil.

Otras mujeres que sufrieron violencia sexual en el D2 por parte la policía provincial fueron aquellas que estaban en situación de prostitución y que diariamente eran llevadas a los calabozos de ese mismo CCD para provocarles ataques diversos a su integridad corporal. Convertida en norma la violencia sexual también para mujeres en situación de prostitución y para las prisioneras políticas de cárceles o centros clandestinos de detención, la misma apuntaba a ultrajarlas y doblegarlas para colocarlas "en posición de víctimas y no de adversarios políticos para redoblar los efectos deshumanizantes, despersonalizantes y destructivos de la estrategia represiva" (D’Antonio, Rodriguez Agüiero, 2017).

$\mathrm{Al}$ analizar algunos casos resonantes de secuestros de mujeres se puede ver con claridad como, además, los interrogatorios a los que ellas eran sometidas por parte de la justicia federal, tuvieron fuertes marcas de género. En el caso de Luz Faingold, por ejemplo, quien fue secuestrada en 1975 siendo menor de edad, las preguntas del ex magistrado Miret, ${ }^{14}$ apuntaban a estigmatizar su conducta en relación a qué hora solía volver a su hogar o si lo hacía sola o acompañada, así como otra serie de presupuestos que dejaban entrever que estas conductas eran indebidas para una mujer. De hecho, el mismo juez se negó a entregar a Luz a sus padres con el argumento de que estaban "divorciados", por lo que en consecuencia resolvió enviarla a un hogar para niñas.

\section{INVISIBILIZACIÓN Y VISIBILIZACIÓN EN LOS CIRCUITOS CARCELARIOS}

Respecto del tema carcelario en otras investigaciones hemos examinado la articulación de género y sexual en el campo de fuerzas que se desarrolló durante los años sesenta y setenta en las cárceles "legalizadas" - las del sistema penitenciario-entre el Estado y las personas apresadas por razones políticas. Si es cierto que la violencia en las cárceles tuvo límites más precisos que en los CCDs, la violencia estatal -fuera legal o ilegal, visible u oculta- estuvo anudada a un proceso político unificado que no puede analizarse de modo fragmentario o en orden al mayor sufrimiento que tuvieron las personas desaparecidas por sobre las apresadas. Nuestra lectura sugiere que esta tensión constituyó una dialéctica que el mismo Estado terrorista alentó y que fue estructurante de la legitimidad que logró alcanzar entre distintos sectores sociales. La violencia ejercida en las cárceles durante este período estuvo en congruencia con el proceso de reforma y especialización que se

14 Miret fue condenado en el año 2017 a prisión perpetua por su actuación como funcionario judicial durante la última dictadura militar. 
dio el sistema penitenciario en estrecha relación con la estrategia represiva más global e integral, congruente con el ideario antisubversivo dominante durante la Guerra Fría tanto en la Argentina como en otros países latinoamericanos. En este marco se aplicaron procedimientos y reglamentos enmarcados en una lógica de "guerra interna" que provocaron un deterioro paulatino de la calidad de vida de las personas apresadas. En este contexto la dimensión de género fue un elemento constituyente de la tecnología disciplinadora ya que tanto los agentes penitenciarios como el personal militar llevaron adelante un dispositivo represivo que tuvo al género como un principio organizador. Asimismo, este produjo en los espacios aún menos visibles como los calabozos de castigo una "subversión" de género en la cual los carceleros llevaban a cabo vejaciones sexuales contra las prisioneras y los prisioneros a contra pelo del discurso público "restaurador", familiarista y heterosexista.

La prisión política y el modo en que ésta se articuló con otros aspectos de la represión estatal se enlazaron en la dinámica particular de esta institución con la relación más general que el régimen entabló con aquello que ocultaba y aquello que dejaba ver. De modo que lo que se mostraba de la prisión legal se desplegó como negación de lo que se ocultaba del encierro y de la represión clandestina. Un mecanismo que tuvo un correlato de género y sexual. Si bien no proponemos realizar una analogía estricta entre el juego de visibilización e invisibilización con que se estructuró la represión estatal con la visibilización e invisibilización de género que operó en la represión hacia las mujeres y varones presos políticos, sin embargo, sí es posible observar en el análisis ciertas correspondencias entre ambos niveles. Por ejemplo, el encierro de las mujeres presas políticas fue el que privilegiadamente ocupó el rol más ostensible se las centralizó en la cárcel de Villa Devoto, una unidad penitenciaria situada en la ciudad metropolitana de Buenos Aires. Este penal fue utilizado por el régimen militar porque las denuncias sobre las violaciones a los derechos humanos que realizaron los exiliados y los sobrevivientes en Europa y Estados Unidos generaron una opinión pública sensible y una atención de los organismos internacionales veedores. Los varones, por su parte, sufrieron un mayor ocultamiento por parte del Estado pues fueron movilizados entre penales con el objetivo de impedir la creación de lazos de sociabilidad estables. Muchos de ellos, además, fueron alojados en penales muy retirados de las ciudades más importantes del país, como es el caso, por ejemplo, del penal de Rawson en la Patagonia o del penal de Resistencia al límite noroeste, en la frontera con el Brasil y el Paraguay. Esto sucedió en franca congruencia con la figura del desaparecido que tuvo como finalidad "despistar" ocluyendo la prueba del delito o sea del cuerpo asesinado y posteriormente desaparecido.

La visibilidad de las prisioneras políticas en una cárcel metropolitana resulta al menos paradójica al colocarse en una "vidriera" a las subjetividades femeninas abyectas que se posicionaban contra las naturales obligaciones domésticas. Una atribución decimonónica que implicaba para estas mujeres, por un lado, que su politización no debía ser tomada en serio por su falta de celo para la política, y, por otro lado, porque no era necesario recluirlas en prisiones de alta seguridad porque su peligrosidad no era tal por su inclinación a la naturaleza hogareña. En este esquema las mujeres eran para los peni- 
tenciarios más "locas" que peligrosas. La concentración de presas políticas en el penal de Villa Devoto puso en juego, además, la masculinidad del régimen mismo, ya que ellas podían ser exhibidas también como trofeos de guerra. El Estado represor mostraba su "magnanimidad" e "indulgencia" al emplazar a las presas políticas en una cárcel urbana, céntrica, moderna y con servicios. Pero ese mismo carácter masculino del Estado era utilizado para imponer la feminización de los varones sometidos a la represión. En todos los casos, en términos de estructura de poder, el agente del encierro se representó como un varón y la víctima del encierro, aunque se enclavara en un cuerpo masculino, como una mujer. Si la representación de la guerra antisubversiva se forjaba entre hombres, como en toda guerra las mujeres eran transformadas en botín de los dominadores. Y es ese juego entre ser mujeres exhibidas y ser mujeres rehenes, la que potenció la idea del régimen de construirlas, además, como botines políticos. ${ }^{\text {La }}$ veneración que se practicaba en el discurso público hacia las mujeres-madres se oponía por el vértice al trato ofrecido a las militantes madres a las que se les sustituía la identidad de sus hijos e hijas.

Las formas de la violencia carcelaria pusieron en evidencia cómo la estructura de género reaparecía insistentemente para reafirmar al poder autoritario y cómo la penalización de la condición de género y la sexualidad fue utilizada como parte de una estrategia para debilitar políticamente a las presas y presos políticos. Si las Fuerzas Armadas y de Seguridad estructuraron su accionar por medio de formas generizadas, es posible afirmar también, que los cuerpos de los agentes de la represión también se inscribieron en el marco del sistema sexo-género imperante. En este sentido, una mención especial merece, por ejemplo, el rol de las celadoras. Vale señalar que la cárcel de Devoto fue originalmente concebida desde un punto de vista arquitectónico para alojar varones, por lo que las mujeres solo serían reunidas allí de modo transitorio u ocasional. De hecho, una de las implicancias sustanciales de esta definición de los espacios de encierro, es que las presas políticas al estar situadas en una cárcel concebida para varones, en tanto habitar en pabellones "anexos", sufrieron altos grados de hacinamiento. En esta etapa de alta concentración de mujeres con distintas trayectorias políticas y sindicales, el servicio penitenciario debió recurrir a la contratación de mano de obra femenina para cubrir algunos de los puestos de control. Aun así, el personal femenino siguió siendo complementario de los carceleros varones. No obstante, la institución penitenciaria profundamente militarizada imprimió en las carceleras una fuerte rudeza varonil y el sustento de su autoridad les implicó, en términos generales, operar a través de la brutalización de su investidura. El servicio penitenciario les confería a estas mujeres autoridad y poder, y en efecto, las habilitaba a una performance aviesa frente a las presas políticas que contaban con una posición de vulnerabilidad.

En el marco del sistema sexo-género, que se reproduce a escala en la institución penitenciaria, lo masculino y lo femenino no encarnaba necesariamente en el cuerpo biológico sino en una posición significante de la economía sexual (Segato, 2003). Por ello, como lo ha explicado Mariana Sirimarco, "la masculinidad bien puede ser ejercida por mujeres". Para el caso de la agencia policial que ha estudiado la antropóloga, sostiene 
que, "no resulta extraño encontrarse con anatomías femeninas que exhiben significantes propios del mundo de lo masculino" (Sirimarco, 2004:71). De este modo, el ejercicio despótico del poder vehiculiza tanto la virilización de la conducta como cierta parodización de los atributos femeninos: un mecanismo de inversión que unge de violencia a sus portadoras, pero que a la vez trata de desubjetivizarlas y transformarlas en mujeres sumisas y obedientes.

El género no es una entidad empíricamente observable sino un registro a partir del cual se inserta una trama de relaciones, por lo que es esperable que las mujeres carceleras socializadas en los valores de una institución histórica y dominantemente masculina, eligiesen posicionarse en ese entramado fuertemente jerárquico a partir de un discurso y una actitud que incorpora el imperativo de la virilidad en el contexto de una relación desigual con otras mujeres.

Como ya se ha señalado, si bien la relación entre la invisibilización y la visibilización de la lógica represiva no es equivalente de la lógica del sistema sexo-género, ambas se entrelazan inextricablemente, al punto de que la invisibilización de las cuestiones de género en el análisis obtura la posibilidad de pensar la relación entre lo visible y lo invisible en la tensión entre el Estado, la violencia y la sociedad civil.

En esta línea es posible afirmar que el centro de la estrategia represiva del régimen militar y de los agentes penitenciarios fue la destrucción ideológica, y que a la vez esta se enlazó, de hecho, con el sistema sexo-género. Se trató de una pretensión de destrucción subjetiva que se manifestó articulada con el ataque al cuerpo físico y a la masculinidad o la feminidad de las personas presas. De modo que las políticas de destrucción de la subjetividad genérica que el régimen practicó de manera oculta en los espacios de encierro (cárceles o centros clandestinos) fueron la contracara de lo que las autoridades militares clamaban en lo que publicitaban de sus discursos donde primaba una prédica restauracionista de los roles de género.

\section{EL ACCIONAR DE LAS CORPORACIONES}

Otro lugar adonde encontramos significativas marcas de género del aparato represivo, en su dimensión legal, es en las gestiones del Poder Judicial. En el caso del Operativo Febrero del '76, ya se ha mencionado, que a Silvia Ontivero, con la anuencia del poder judicial provincial, en octubre de 1977, el padre de su hijo consiguió que se le quitara la patria potestad por medio de la figura de "abandono de hogar". Esto le impidió a Silvia verlo por largos seis años. Por otra parte, luego de su cautiverio en el D2, Silvia fue llevada a declarar frente al juez federal Miret. Y ella le expresó: "Doctor, mire cómo estoy, me han violado, me han golpeado”, a lo que el juez le respondió: “¿No te habrás caído?”. El caso Ontiveros es sólo uno de los ejemplos de las múltiples acciones en las que la justicia federal fue cómplice y responsable de los delitos de lesa humanidad. De hecho, en 2017, fueron condenados a prisión perpetua cuatro ex jueces federales mendocinos tras ser acu- 
sados de formar parte del aparato terrorista estatal. Como a las demás mujeres integrantes de este operativo, Stella Maris Ferrón, luego de 18 días de cautiverio, fue llevada, en este caso, ante el juez Carrizo. Stella detalló en el juicio: "Yo sólo le pedía que me devolvieran a mi hija y Carrizo me dijo que no sabía que yo iba a declarar y que por eso no había averiguado nada de la nena... me interrogaba dónde estaba mi esposo". Su marido, José Antonio Rossi, se encontraba viviendo en la clandestinidad, y posteriormente el 27 de mayo de 1976, fue secuestrado en un café céntrico mendocino, continuando hasta el día de hoy desaparecido. Por último, Vicenta Zárate, luego de los padecimientos a los que fue sometida en el ex D2, fue trasladada a la central policial, donde el secretario del juzgado le comunicó que había sido encapuchada "por razones de seguridad".

Otra corporación que salvo excepciones actuó de modo incondicional con el terrorismo de Estado fue la de la prensa. En trabajos anteriores hemos analizado el papel que el diario Los Andes, por ejemplo, jugó durante los años de la última dictadura militar (Rodríguez Agüero, 2016). En esta ocasión traemos a colación el tratamiento que el diario ofreció sobre una militante que fue secuestrada y cuya hija le fue arrebatada. Este caso sirve, además, para observar una vez más, la práctica de desmaternalización y la doble cara del discurso del régimen al respecto. Así como de las violaciones cometidas contra militantes mujeres y los secuestros de embarazadas no hubo registro, es de notar la forma en la que Los Andes relató el asesinato del poeta y militante montonero Paco Urondo, el secuestro de Alicia Raboy, su compañera, y el intento de apropiación de su hijita: Ángela Urondo Raboy. Según el jornal, Urondo fue "abatido" la noche del 17 de junio "como resultado de la actuación de las fuerzas del orden" (Los Andes, Mendoza, 19/6/1976). Por su parte, su mujer herida habría huido y habría dejado abandonado en el auto "un niño" (sic) de un año. El título de la nota era "Abatieron en Mendoza a un delincuente subversivo. Usó como escudo a un niño". La crónica ponía especial acento en la falta de humanidad de los "subversivos":

"Este proceder, de utilizar niños como escudo para llevar a cabo sus asesinatos, exponiéndolos a ser heridos o muertos durante la acción y abandonándolos a su suerte ante el menor fracaso, habla claramente de la poca moral y desviados sentimientos que animan a estos delincuentes subversivos" (Los Andes, Mendoza, 19/6/1976).

En el discurso militar, los "enemigos", identificados como: "delincuentes, terroristas, subversivos, apátridas", encarnaban la puesta en cuestión de todos los valores de la moral, asimilados a los de la religión católica (Ciriza y Rodríguez Agüero, 2015). Un ejemplo claro sobre cómo esta perspectiva permite visualizar las aristas estructurales diversas del accionar represivo lo encontramos en la construcción del enemigo interno. Tal como señala Valeria Manzano, los componentes sexuales y de género son esenciales para comprender y explicar que la amenaza que representaba dicho enemigo atañía el orden político, socio-económico, cultural y sexual por igual. Según la óptica de las Fuerzas Armadas y del nacionalismo católico, existía una ligazón entre las ideas de ju- 
ventud, sexualidad desviada y subversión, todas características inherentes al enemigo interno (Manzano, 2015: 2). La construcción de esta idea del enemigo, que es deudora de tradiciones anteriores, y que entre 1955 y 1976 se fue desplazando de la figura del comunista hacia una compleja entidad con límites poco precisos denominada "subversión", se cristalizó en los años previos al golpe en un abanico de actores "sospechosos" que podían llegar a perturbar al sistema. A su vez, a medida que se acentuaba la radicalización política, el nacionalismo católico, sectores de la prensa y de las Fuerzas Armadas promovieron una imagen genérica y sexualizada que tuvo gran repercusión, así como brutales consecuencias para las militantes que fueron secuestradas: la "guerrillera", por ejemplo, fue una figura en la que se resumían las múltiples amenazas y servía para enfatizar la incompletitud del proyecto político-cultural que el bloque conservador había intentado imponer durante los '60” (Manzano, 2015: 17). Las mujeres, según esta versión eran particularmente crueles, capaces de abandonar a sus hijos e hijas y exponerlos al peligro. Como ha señalado en sentido similar, Marta Vasallo, las guerrilleras eran "mujer [es] que se salía[n] de su rol hasta el punto no sólo de aspirar a alguna forma de poder público sino de elegir además la vía de las armas, terreno exclusivo de la agresividad y heroísmo varonil" (Vasallo, 2009: 18). Alicia Raboy, como tantas otras, fue demonizada a través de la crónica periodística al ser acusada de haber utilizado a su hijita que la acompañaba en su automóvil como "escudo humano", y también de haberla abandonado, cuando en realidad la niña le fue arrebatada y ella secuestrada y finalmente desaparecida (Ciriza y Rodríguez Agüero, 2015).

Finalmente, si bien no serán abordadas en este trabajo, deben mencionarse otras dos corporaciones que formaron parte intensa de la trama represiva. Nos referimos a la Iglesia Católica y a los grupos de médicos, en cuyo accionar se pueden hallar marcas sexo genéricas, tales como la participación de los galenos en los partos de las maternidades clandestinas de los CCD (con la posterior desaparición de las madres y apropiación de los bebés) o la realización de abortos y legrados sin anestesia. También es importante reparar en la presencia que los capellanes tuvieron en las sesiones de tortura durante los interrogatorios, y en su participación directa en la apropiación de bebés de mujeres desaparecidas.

\section{ALGUNAS REFLEXIONES FINALES}

Michel Perrot ha señalado a partir del caso de la España franquista y de la Francia de Vichy, que los regímenes totalitarios hacen "de la diferencia de los sexos y su jerarquía un principio absoluto" propiciando un "retorno al orden sexual" (Perrot, 2003:125). Para el caso argentino, también la última dictadura militar implicó, al menos en el orden discursivo, una restauración conservadora que puso especial énfasis en intentar revertir "la subversión de las relaciones intergenéricas" que empezaban a tomar cuerpo durante las décadas de los 60 y los 70. 
A partir de las investigaciones empíricas que hemos llevado adelante, podemos sostener, que la ausencia en el análisis social de la dimensión de género y sexual ha conducido a soslayar una serie de elementos vitales para comprender de conjunto lo sucedido en el pasado reciente. Para el caso de la historia de la represión, y en particular, para el análisis de la misma durante los años de la última dictadura militar, la perspectiva de género facilita tornar visibles ciertos objetos y prácticas sociales que, lejos de ser secundarios, adquieren un papel particularmente central y contribuyen a construir una explicación integral de los procesos históricos. Los métodos de captura, la organización sexuada de la persecución y de los lugares de detención, y el trato generizado que tuvieron los castigos y la violencia sexual aplicada sistemáticamente ponen en evidencia una forma de funcionamiento estatal propio de esta etapa. Pero también es una lente sugerente para comprender el accionar represivo de los miembros de las Fuerzas Armadas y de las Fuerzas de Seguridad y el papel que cumplieron los perpetradores que provenían de las ciencias médicas, la psicología e incluso del Poder Judicial.

En este trabajo abordamos algunos aspectos del estudio de la represión estatal a partir de la dimensión de género y sexual con el fin de articularlo, conjuntamente, con otros elementos explicativos propios del orden político, ideológico y cultural. La perspectiva de género reflexiona, por un lado, acerca de las formas en las que se constituyen históricamente las instituciones y los roles y funciones de los agentes de la represión estatal; y por otro, refina la comprensión de los mecanismos en los que esta se vincula. Poner en foco esta dimensión en la construcción, desarrollo, aplicación y resultado de una política estatal nos permite una interpretación que va más allá de concebir a esta como un mero producto mecánico del plano discursivo del régimen o de la crueldad inmanente de los perpetradores. De tal modo, nuevos sujetos, prácticas, periodizaciones y dimensiones se reponen en el entramado represivo. Asimismo, estudiar estos procesos en las diferentes escalas de análisis, obliga a prestar atención a las marcas locales en torno a las formas en que la represión estatal se aplicó, y permite poner en cuestión algunos de los modelos explicativos "nacionales" que durante años fueron hegemónicos en el ámbito académico.

Un último aspecto que merece ser subrayado es que, en términos generales, en los análisis de género y de la sexualidad en las Ciencias Sociales y Humanas se ha tendido a enfatizar el carácter emancipatorio de la "subversión" en términos de roles, identidades, prácticas y representaciones. Y si bien no se trata de negar que la desestabilización de una estructura sexo-genérica opresiva puede ser efectivamente liberadora, en este caso lo que deseamos subrayar, es que no todas las impugnaciones tienen efectivamente un carácter redentor. En esa dirección es posible alegar que, la dificultad de visualizar en el análisis la desestabilización del orden de género llevada adelante por el régimen militar en los espacios de encierro tanto sea en centros clandestinos de detención como en cárceles legalizadas, debe ser considerada como un obstáculo epistemológico que no contribuye con una comprensión cabal de las dinámicas represivas más generales del período. 


\section{BIBLIOGRAFÍA}

Aucía, A; Barrera, F, Berterame, C, Chiarotti, S, Paolini, A. y Zurutuza, C. (2011), Grietas del silencio. Una investigación sobre la violencia sexual en el marco del terrorismo de Estado, CLADEM, Insgenar, Buenos Aires.

Bacci, C, Capurro M., Oberti, A., Skura S. (2014): "Entre lo público y lo privado: los testimonios sobre la violencia contra las mujeres en el terrorismo de Estado en Argentina", en Clepsidra, Revista Interdisciplinaria de Estudios sobre la Memoria, (IDES), Buenos Aires, Año 1, No 1

Balardini, L; Oberlin, A. y Sobredo, L. (2011) "Violencia de género y abusos sexuales en centros clandestinos de detención. Un aporte a la comprensión de la experiencia Argentina”, en Hacer justicia. Nuevos debates sobre el juzgamiento de crímenes de lesa humanidad en la Argentina, Siglo XXI, Buenos Aires.

Berterame, M. C. (2011): "Reparación del daño a las víctimas de violencia sexual. Una mirada desde el feminismo" Aucía et al. (comp.) Grietas del silencio. Una investigación sobre la violencia sexual en el marco del terrorismo de Estado, CLADEM, Insgenar, Buenos Aires.

Ciriza, A. (2014) "Sobre las violaciones cometidas en los centros clandestinos de detención como delitos de lesa humanidad", en Sin Permiso. Disponible en: <http://www. sinpermiso.info/textos/index. php?id=3807>, [Consulta: 7 de setiembre de 2014].

Ciriza A. y Rodriguez Agüero, L. (2015): "La revancha patriarcal. Cruzada moral y violencia sexual en Mendoza (1972-1979)", Avances del Cesor, Rosario; vol. XII.

D’Antonio D. (2016): La prisión en los años setenta: Historia, género y política, Ed. Biblos, Buenos Aires.

D’Antonio, D. (2012), “Los presos políticos del penal de Rawson: un tratamiento para la desubjetivación. Argentina (1970 1980), en Anos 90, Dossiê Ditaduras de Segurança Nacional no Cone Sul, Porto Alegre, 2012, V. XIX, №. 35

D’Antonio, D. (2011), "Políticas de desarticulación de la subjetividad sexual y de género practicadas en la cárcel de Villa Devoto durante la última dictadura militar argentina (1976-1983), en Revista Estudios, N 25.

D’Antonio D. y Viano C. (2018): “A propósito de la historia reciente argentina, la historia de las mujeres y los estudios de género: intersecciones y desafíos”, La historia reciente Argentina: Balances de una historiografía pionera en América Latina, Imago Mundi, Buenos Aires.

D’Antonio, D. y Rodríguez Agüero L. (2017) "Una lectura de la represión desde los bordes de género", en III Jornadas de la Red de Estudios sobre Represión y Violencia Política, Universidad Nacional de La Plata, Buenos Aires.

Manzano, V. (2015): “Sex, Gender and the Making of the 'Enemy Within' in Cold War Argentina, Journal of Latin American Studies, Cambridge, $\mathrm{N}^{\circ} 47$.

Perrot, M. (2008): Mi historia de las mujeres, FCE, Buenos Aires.

Rodríguez Agüero, L. (2016): "Los Andes, Antonio Di Benedetto y la violencia paraestatal. Mendoza, 1973-1976”, Revista de Historia, № 17, noviembre 2016, pp. 122- 
144. Departamento de Historia, Facultad de Humanidades, Universidad Nacional del Comahue.

Segato, R. (2003): Las estructuras elementales de la violencia, Prometeo, Buenos Aires.

Sirimarco, M. (2004): "Marcas de género, cuerpos de poder. Discursos de producción de masculinidad en la conformación del sujeto policial", Cuadernos de Antropología Social, . $^{\circ}$ 20, FFyL-UBA.

Sutton, B. (2018): Surviving State Terror: Women's Testimonies of Repression and Resistance in Argentina, NYU Press, Estados Unidos.

Vasallo, M. (2009): “Militancia y transgresión” en Andújar, A., D’Antonio, D., Gil Lozano, F., Grammático K. y Rosa, M. L. (compiladoras), De minifaldas, militancias y revoluciones. Exploraciones sobre los 70 en la Argentina, Luxemburg, Buenos Aires.

Vasallo, M. (2011): "Introducción”, Grietas del silencio. Una investigación sobre la violencia sexual en el marco del terrorismo de Estado, op.cit. 